\title{
Pemanfaatan Ruang pada Lahan Terbatas untuk Pembangunan Rumah Susun
}

\author{
Aldino Fajri dan Vincentius Totok Noerwasito \\ Departemen Arsitektur, Fakultas Teknik Sipil dan Perencanaan, Institut Teknologi Sepuluh Nopember (ITS) \\ e-mail: vtonoer@arch.its.ac.id
}

\begin{abstract}
Abstrak-Tingginya angka selisih hunian yang dibutuhkan dengan hunian yang tersedia atau yang biasa disebut 'backlog' merupakan suatu masalah yang sudah tidak asing di kota-kota besar seperti Jakarta, S urabaya, Medan, dan lain-lain. S alah satu penyebabnya yaitu minimnya ketersediaan lahan di kota-kota besar tersebut. Masalah inipun juga disebabkan oleh banyaknya masyarakat yang melakukan urbanisasi ke kota-kota besar yang tergolong sebagai Masyarakat Berpenghasilan Rendah (MBR) namun, mereka tidak memiliki finansial yang cukup untuk membeli atau menyewa rumah sehingga seringkali membuat permukiman-permukiman kumuh seperti di bantaran sungai dan kolong jembatan yang menyebabkan masalah baru di kota. Dengan menggunakan metode datascape tentang penyusunan rumah susun yang sudah ada saat ini dapat ditarik kesimpulan jika penyusunan rumah susun yang sudah ada kurang dapat menyelesaikan masalah tersebut. Oleh karena itu, dibuat sebuah susunan baru dengan menyilang diagonal untuk lebih memanfaatkan lahan yang tersedia. Namun, di lahanpun juga seringkali terdapat masalah, salah satunya adalah banjir. Sehingga konsep rancangan rumah susun yang ada nantinya juga harus tanggap akan permasalahan tersebut. Diantaranya, dengan menaikkan lahan rancang, membuat sebuah danau resapan untuk menampung air hujan dan membuat sungai disekeliling bangunan untuk memperluas wadah penampungan saluran pematusan kota yang sudah ada.
\end{abstract}

Kata Kunci-Masyarakat berpenghasilan rendah, rumah susun, silang diagonal.

\section{PENDAHULUAN}

ELISIH antara hunian yang dibutuhkan dengan hunian Nyang tersedia di kota besar seperti Jakarta masih cukup tinggi [1]. Ketersediaan lahan pun juga menjadi salah satu penyebab dari masalah ini. Tingginya angka urbanisasi pun juga turut serta menjadi penyebab masalah ini, karena para pelaku urbanisasi yang pindah ke kota besarcukup banyakyang tidak bisa membeli/menyewa rumah dikarenakan kondisi finansial mereka. Menurut Pasal 1 Angka 24 UU Nomor 1 Tahun 2011 tentang Perumahan dan Kawasan Permukiman, "Masyarakat berpenghas ilan rendah yang selanjutnya disingkat MBR adalah masyarakat yang mempunyai keterbatasan daya beli sehingga perlu dukungan pmerintah untuk memperoleh rumah" [2]. Hal ini pun menjadikan kebanyakan dari pelaku urbanisasitergolong MBR.

Permasalahan 'backlog' ini harus segera diselesaikan karena banyak dari MBR yang membuat permukiman-permukiman liar seperti di kolong jembatan dan di bantaran sungai, yang nantinya menyebabkan suatu permasalahan baru di kota besar sehingga aktifitas masyarakat lainnya terganggu.

\section{METODA PERANCANGAN}

Pendekatan desain yang digunakan adalah high-density development dimana suatu rancangan harus ditempatkan di lokasi yang strategis dan dapat memnfaatkan ruang sebanyakbanyaknya pada lahan yang terbatas atau sempit [3]. Kemudian juga berdasarkan perilaku MBR yang cenderung tidak memiliki barang-barang yang mewah dan terlalu besar maka lorong/sirkulasi yang dibuat tidak terlalu besar serta meminimalisasi parkiran mobil dimana MBR pada umunya tidak mampu untuk membeli mobil.

Berdasarkan kriteria dari pendekatan tersebut, digunakan metode desain datascape dengan mengumpulkan data-data sebagai dasar untuk mendesain [4]. Berdasarkan beberapa pengamatan yang didapat, susunan rumah susun yang telah dibangun pada umunya dibuat secara terpis ah menjadi beberapa bangunan yang disusun terpisah baik sejajar maupun tegak lurus. Susunan ini dirasa kurang efektif untuk memanfaatkan lahan yang tersedia.

Oleh karena itu rancangan disusun menyilang mengikuti sumbu diagonal pada lahan. Susunan ini pun dirasa cukup efektif untuk memanfaatkan lahan yang tersedia sehingga lahan yang terbangun akan menjadi lebih banyak. Selain pada sisi penyusunannya, metode ini juga digunakan untuk menyusun ruang yang dibutuhkan pada rancangan. Berikut merupakan aktifitas yang akan diwadahi:

1) Rumah tangga

Rancangan harus dapat mewadahi aktifitas keluarga dari warga rusun. Keluaran: Unit Hunian.

2) Sosial

Rancangan harus dapat mewadahi aktifiitas warga rusun. Keluaran: Fasilitas bersama yaitu aula (tempat berkumpul dan taman bermain anak-anak.

3) Administrasi

Rancangan harus dapat menunjang kegiatan administrasi dan pengelolaan rusun. Keluaran: Fasilitas penunjang yaitu kantor administrasi dan kantor RT.

4) Perniagaan

Sebagai salah satu mata pencaharian warga rusun dan sebagai pemasok kebutuhan warga. Keluaran: Fasilitas penunjang yaitu pertokoan/pasar.

5) Ibadah

Mewadahi warga rusun untuk melakukan ibadah bersama sehari-hari. Keluaran: Fasilitas bers ama yaitu masjid/musholla

6) Parkir

Mewadahi penghuni rusun untuk memarkirkan dan meletakkan kendaraannya. Keluaran: area parkir. 
Kemudian metode ini juga digunakan untuk menyusun ruang-ruang yang dibutuhkan dalam satu unit rumah susun. Hasilnya adalah sebagaiberikut:

1. Makan \& berkumpul

MBR tidak terlalu memerlukan ruangan khusus untuk makan sendiri atau pun untuk berkumpul sendiri, jadi kedua fungsi tersebut dapat dis atukan dalam satu ruangan.

\section{Tidur}

Dibutuhkan kamar tidur untuk mewadahi aktifitas istirahat. Kamar tidur ini diperlukan sebanyak 2, yaitu untuk orangtua dan untuk anak.

\section{Memasak}

MBR cenderung untuk memasak makanan sendiri daripada membelinya di tempat makan /kedai makan.

4. Mencuci dan menjemur pakaian

MBR cenderung mencuci pakaiannya sendiri dan tidak menggunakan jasa pencucian/laundry sehingga dibutuhkan ruang untuk mewadahi aktifitas tersebut.

5. Mandi dan buang kotoran

Tentunya dibutuhkan sebuah kamar mandi untuk mewadahi aktifitas pembersihan badan.

\section{HASIL DAN EKSPLORASI}

Hasil rancangan yang dibuat sesuai dengan keluaran dari metode yang digunakan. Sehingga salah satu dampaknya merupakan bentuk siteplan bangunan menjadi menyilang diagonal agar dapat memanfaatkan ruang yang tersedia pada lahan. Kemudian sebagai pencegahan terhadap bencana di lingkungan sekitar yaitu banjir maka lahan pada objek rancang dinaikkan setinggi 1,5 meter. Lalu, pada bagian tengah rancangan dibuat sebuah danau resapan yang berfungsi untuk menampung air hujan serta dibuat sungai di s ekeliling objek rancang yang berfungsi untuk memperluas wadah penampungan saluran pematusan kota yang sudah ada. Hal ini juga dimaksudkan agar lingkungan di sekitar objek rancang tidak menjadi semakin banjir karena kehadiran objek nantinya.

Untuk meminimalisasi kerugian yang disebabkan oleh banjir jika nantinya terjadi banjir yang cukup besar, maka unit hunian diletakkan di lantai 2-4 sehingga pada lantai 1 hanya terdapat fasilitas bersama dan penunjang. Kemudian untuk unit huniannya dibuat seluas $33 \mathrm{~m} 2$ dengan ukuran $6 \mathrm{~m} \times 5,5 \mathrm{~m}$. Perancangan tersebut juga dimaksudkan agar penghuni rusun nantinya yaitu MBR tidak membawa atau membeli barangbarang besar yang tergolong mewah sehingga ruang untuk aktifitas utama dapat terwadahi.

Pada rancangan lansekap bangunan dibagi menjadi 2 yaitu area parkir kendaraan dan area taman. Untuk area parkir ini sendiri juga dibagi menjadi area parkir motor dan parkir mobil. Untuk area parkir motor dibuat mengikuti lahan yang dinaikkan 1,5 meter. Area parkir mobil diminimalisasi karena MBR pada umumnya dan seharusnya tidak memiliki finansial yang cukup untuk memiliki mobil. Pada lantai atas bangunan dibuat roof garden, hal ini dimaksudkan juga agar membentuk perilaku yang sehat untuk penghunirusun nantinya.

\section{KESIMPULAN}

Dalam merancang suatu bangunan yang berfungsi sebagai hunian diperlukan sebuah metode dan pendekatan desain untuk menyelesaikan permasalahan yang ada. Objek rancang disusun secara menyilang diagonal agar dapat memenfaatkan ruang yang tersedia pada lahan yang terbatas dengan efektif. Objek rancang juga disesuaikan dengan perilaku MBR dengan menyempitkan lorong sirkulasi serta meminimalisasi parkiran mobil. Objek rancang juga tanggap akan bencana pada lingkungan lahan yaitu banjir sehingga lahan rancangan dinaikkan setinggi 1,5-meter $\mathrm{d}$ an dibuat danau resapan serta sungai pada sekeliling lahan untuk menampung air hujan dan memperluas wadah saluran pematusan kota.

\section{LAMPIRAN}

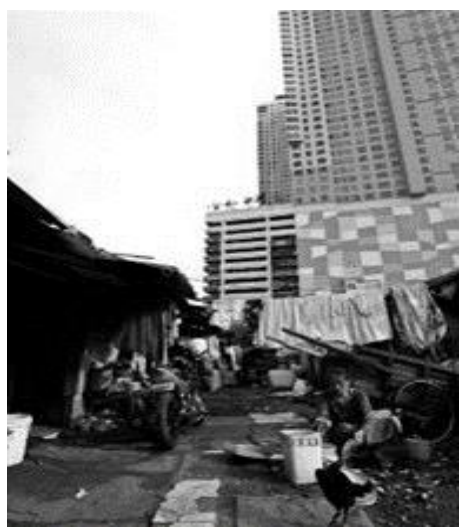

Gambar 1. Permukiman kumuh di Kebayoran Baru, Jakarta. (sumber: Papaparan Program Penyediaan Rusun, Direktorat Rumah Susun 2016).

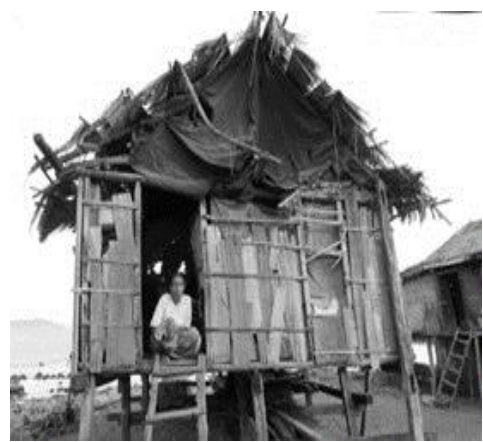

Gambar 2. Rumah tidak layak huni di permukiman nelayan, Labuan Bajo (sumber: Papaparan Program Penyediaan Rusun, Direktorat Rumah Susun 2016).

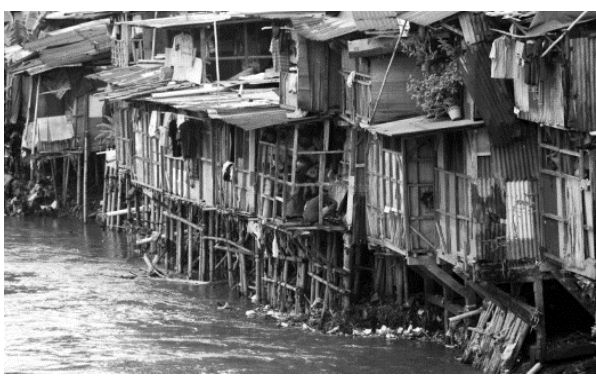

Gambar 3. Rumah tidak layak huni di bantaran sungai. (sumber: images.google.com). 


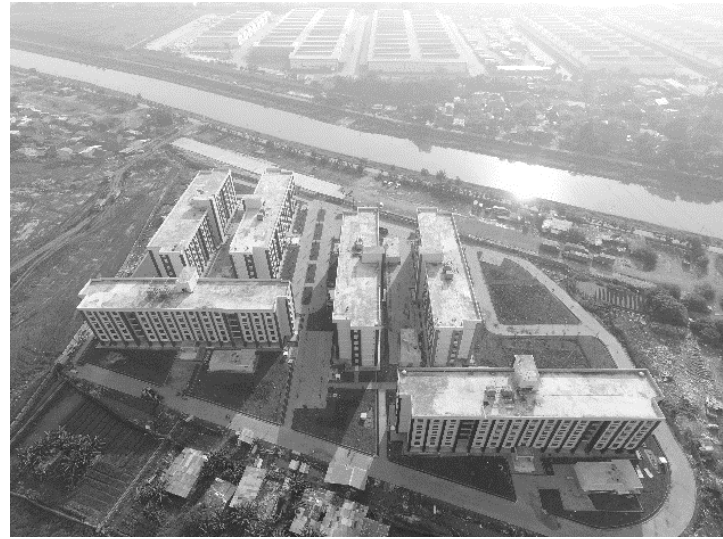

Gambar 4. Contoh penyusunan rusun Rawabebek, Jakarta. (sumber: Dokumentasi Direktorat Rumah Susun)

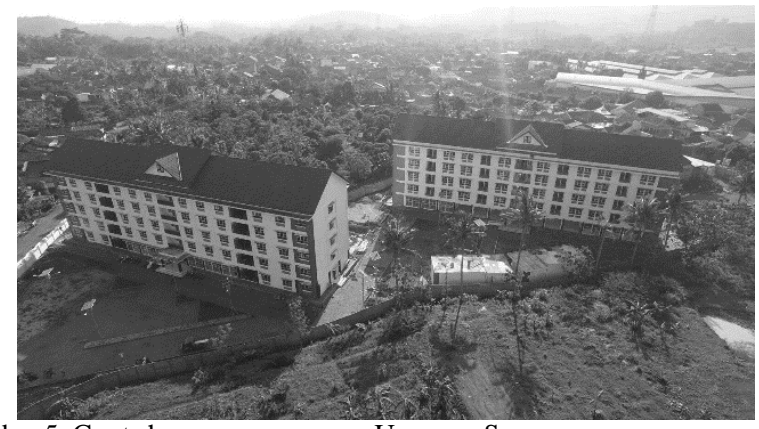

Gambar 5. Contoh penyusunan rusun Ungaran, Semarang. (sumber: Dokumentasi Direktorat Rumah Susun)

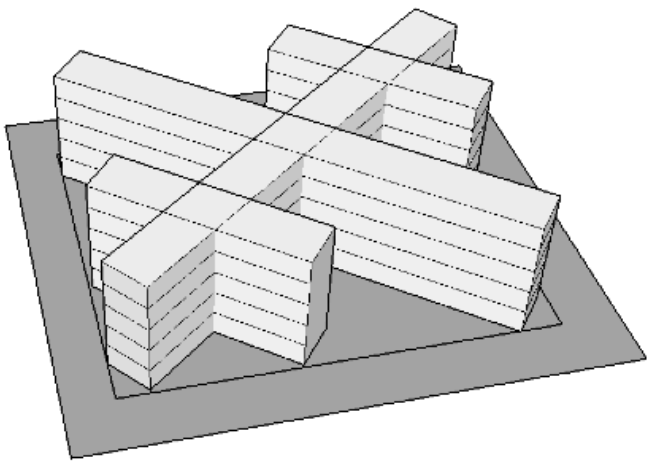

Gambar 6. Konsep penyusunan rusun secara menyilang diagonal. (sumber: Dokumentasi Pribadi)

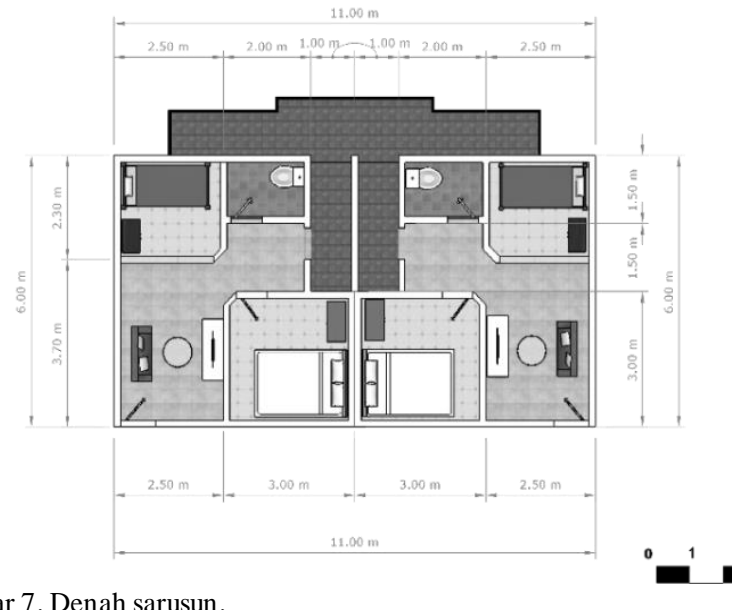

Gambar 7. Denah sarusun.

(sumber: Dokumentasi Pribadi)

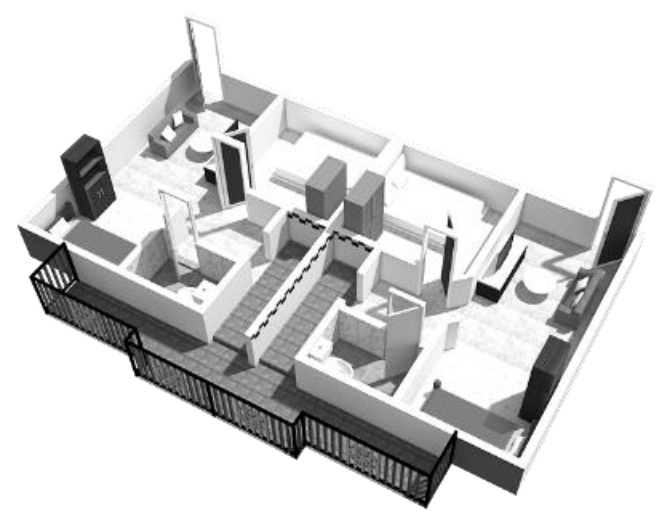

Gambar 8. Perspektif sarusun.

(sumber: Dokumentasi Pribadi)

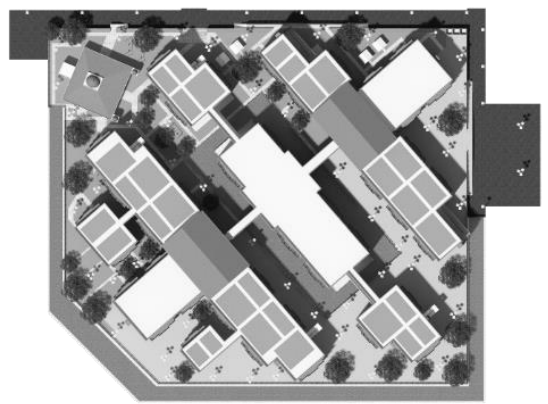

Gambar 9. Siteplan objek rancang. (sumber: Dokumentasi Pribadi)

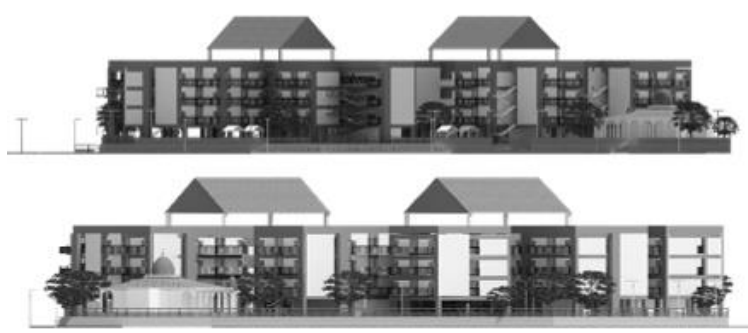

Gambar 10. Tampak objek rancang.

(sumber: Dokumentasi Pribadi)

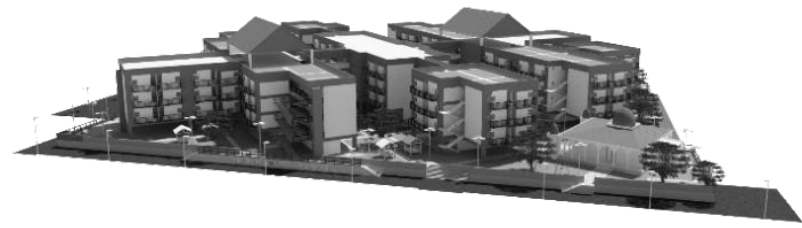

Gambar 11. Perspektif mata burung objek rancang. (sumber: Dokumentasi Pribadi)

\section{DAFTAR PUSTAKA}

[1] Kementerian PU \& PR, "Buku Saku Direktorat Rumah Susun Kementerian PU \& PR 2016.,"Jakarta, 2016.

[2] Pemerintah Republik Indonesia, "Undang-undang Republik Indonesia No. 1 T ahun 2011 tentang Perumahan dan Kawasan Permukiman," 2011.

[3] D. Sharp, "High-Density Development Strategies for More Sustainable Growth," 2013. [Online]. Available: http://www.naiop.org/en/Magazine/2013/Summer-2013/DevelopmentOwnership/High-Density Development-Strategies-for-More-SustainableGrowth.aspx.

[4] MVRDV, “Design Philosophy.” [Online]. Available: https://www.mvrdv.nl/en/about/Design_Philosophy. 